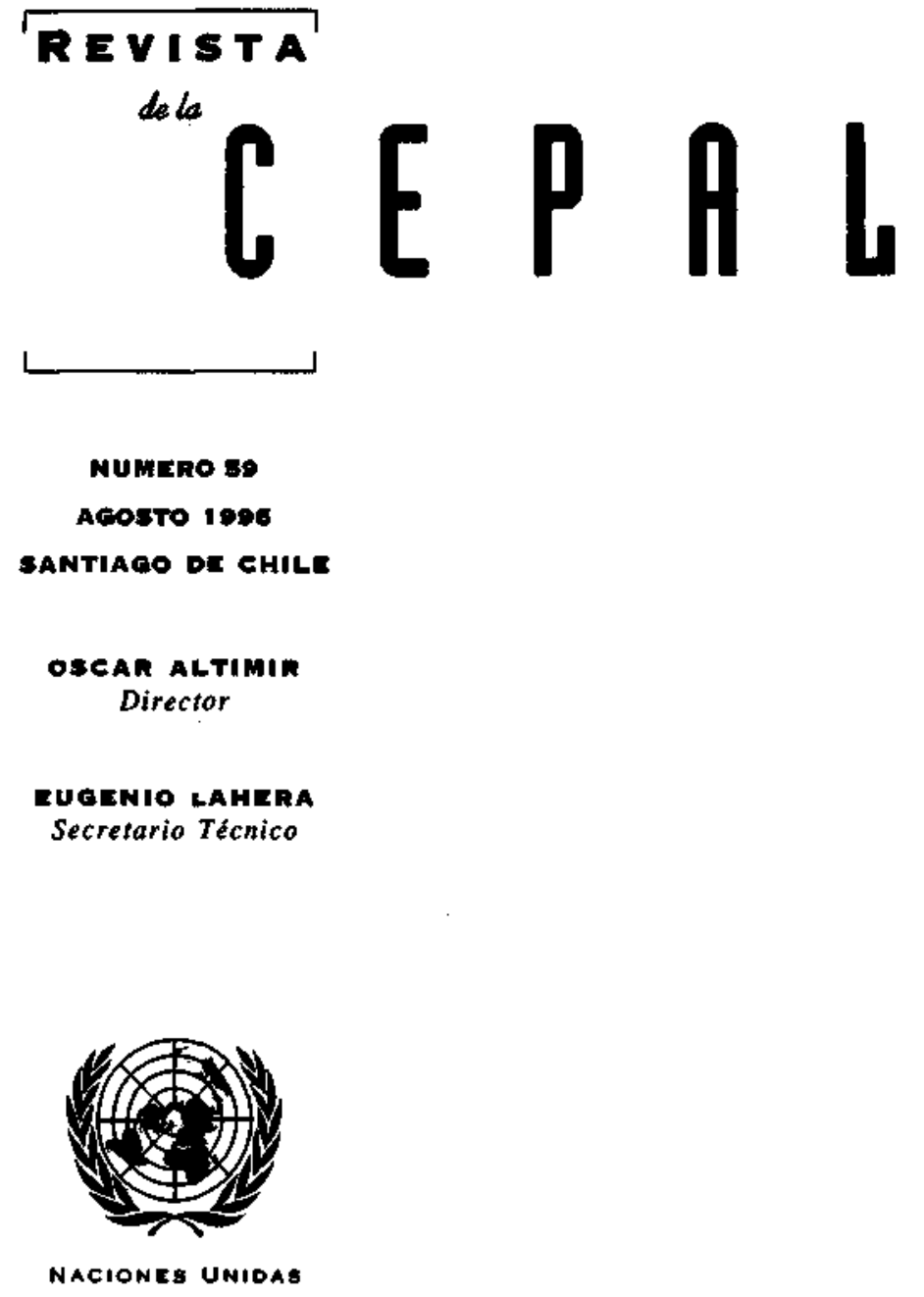


Interacciones entre macro y microeconomía

Gert Rosenthat

Politica económica, instituciones y desarrollo productivo en América Latina

Osvaldo Rosales

Competitividad sistémica: nuevo desafío para las empresas y la política

Klaus Esser, Wolfgang Hillebrand, Dirk Messner y Jörg Meyer-Stamer

La formación de habilidades báslcas y la capacitación para el trabajo productivo

Guillermo Labarca

Los fondos de inversión social en América Latina

Gabriel Siri

Mercados de derechos de agua: componentes institucionales

Miguel Solanes

Los países del Caribe y el área de libre comercio de las Amérlcas

Trevor Harker, Sidya Ould El-Hadj y Lucio Vinhas De Souza

La experiencia argentina: ¿desarrollo o sucesión de burbujas?

Hugo Nochteff

Posibilidades y límites de la reforma en la gestión de

la salud en Chile

Ana Sojo

Orientaciones para los colaboradores de la Revista de la CEPAL 


\section{Mercados de derechos de agua: componentes institucionales}

\section{Miguel Solanes}

Asesor en Derechos

de Aguas, CEPAL
El agua es un recurso escaso que tiene valor económico e importantes funciones ecologicas y sociales. Por esta razón es normalmente un bien de dominio público del Estado, sobre el cual se conceden derechos de uso a particulares. Estos derechos están protegidos habitualmente por cláusulas constitucionales sobre la propiedad privada, pues se considera que el sector privado no invierte sin garantía de títulos. En contrapartida, el agua otorgada en uso debe ser efectivamente utilizada con un fin socialmente beneficioso; en caso contrario se revocan los derechos. Si bien hay algunos sistemas en que los usos son incondicionados, esto no es común. Los elementos legales que influyen en la estabilidad de los derechos son estructurales: entre ellos están las normas que aseguran la estabilidad, las que hacen a la transferencia de los derechos y las referidas al reconocimiento de usos y derechos preexistentes. Este último es fundamental, en la medida en que reconoce economías asentadas y asegura estabilidad social. Puesto que el agua tiene un valor economico, su transferencia es un aspecto importante para asegurar su optimización económica; los profesionales del sector deben estar abiertos a la idea de la transferencia de derechos. Como estas transferencias tienen efectos sobre terceros, sobre la estabilidad social y sobre el medio ambiente, los países con sistemas maduros de transferencia regulan tales efectos. Las regulaciones también tienen por objeto proteger los medios de subsistencia de los sectores más marginales de la población, entre otros los aborígenes. Esto es coherente con la dinámica económica, ecológica y social de los tiempos. 


\section{I}

\section{Introducción}

El agua dulce es un recurso natural escaso, que por efectos de distintos fenómenos se vuelve cada vez más valioso económicamente y más esencial en términos de servicios y necesidades sociales.

Para su manejo y conservación adecuados se necesitan instrumentos legales idóneos, que aseguren por un lado la inversión privada en el desarrollo del potencial económico del recurso, y que posibiliten por otro su adecuado control en función de objetivos ambientales y sociales.

Los marcos institucionales y legales de los diferentes países determinan las maneras en que se motiva al sector privado a invertir en el desarrollo de los recursos hídricos. En este sentido la legislación cumple un papel estructural de ingeniería socioeconómica, ya que configura la forma en que los agentes economicos se vinculan con los recursos productivos. Esta función de las normas legales tiene gran importancia, porque impulsa a los operadores económicos a cumplir cierto tipo de tareas e influye en la forma en que lo hacen (si estas actividades les son económicamente beneficiosas, los operadores las realizan por voluntad propia, sin necesidad de coerción pública). Este grupo de normas son las que determinan la estabilidad y la flexibilidad de los derechos de los agentes económi$\cos$ sobre las aguas. Se las denomina normas estructurales puesto que determinan la matriz básica de derechos sobre el recurso.

En paralelo, y como consecuencia de las características físicas, químicas y biologicas del agua - recurso en flujo constante, con un gran potencial para generar externalidades negativas, o servir de agente para transferirlas, con un papel ecológico crucial, y susceptible de uso múltiple si se planifica apropiadamentela legislación de aguas incorpora una serie de normas regulatorias ${ }^{1}$ del modo de ejercicio de los derechos particulares, a fin de asegurar que las formas de uso no signifiquen desperdicio ni deterioro del recurso, no

\footnotetext{
'Esta denominación, y la diferencia sustantiva y funcional que implican las diferentes normas, ha sido aceptada en diferentes documentos de organismos internacionales, incluyendo los del seminario sobre legislación de aguas organizado por el Banco Mundial y la CEPAL en septiembre de 1994 (Banco Mundial/CEPAL, 1994; Naciones Unidas, Consejo Económico y Social, 1993 y 1994).
}

fomenten especulación ni monopolios ni causen rigidices irreversibles en su asignación.

El desafío del derecho de aguas $-y$ su virtudes encontrar el balance adecuado entre las normas estructurales y las regulatorias. Con las primeras se trata de preservar una estabilidad y flexibilidad de los derechos que asegure, o por lo menos promueva, el máximo rendimiento económico de ellos. Con las segundas se busca asegurar el uso eficiente y ordenado del agua, preservar su capacidad de producción, su rol ecológico y su calidad, y prevenir la constitución de monopolios y la especulacion. Las normas estructurales no deben desembocar en monopolios o deterioros ambientales. Las regulatorias no deben ahogar el sistema económico.

En este estudio se trata de identificar ios diversos modos en que las legislaciones de distintos países del mundo han abordado estos aspectos. Para ello se analizan diversos temas, como sistemas de derechos sobre aguas, medidas de protección, mercados de derechos de aguas, sistemas de información, caducidad de derechos, sistema de manejo de información, organización para la administración del recurso y otros.

Normalmente, los sistemas de derechos sobre aguas no constituyen bloques legales que reflejen posiciones ideológicas absolutas. La necesidad de lidiar con problemas concretos ha llevado a las legislaciones a adoptar las medidas requeridas por la situación concreta, el bienestar general y la ética pública. Así por ejemplo, todos los sistemas, excepto algunos casos contados y en vías de cambio, reconocen derechos privados al uso de las aguas, pero los sujetan a ciertas condiciones (pago de derechos, uso conforme a permisos, restricciones en función de aspectos ambientales y sociales, etc.). En algunos sistemas se autoriza la comercialización de derechos de agua, pero en todos ellos se exige que el uso de las aguas involucrado sea efectivo y beneficioso, con el propósito de evitar monopotios y especulación; incluso se requiere que las transferencias sean autorizadas por autoridades administrativas o judiciales, se sujeten a publicidad, se registren y, eventualmente, se sometan a condiciones que el derecho originario no tenía. El derecho a transferir no tiene entidad legal si no va asociado al uso efectivo y beneficioso del recurso. 


\section{II}

\section{Elementos estructurales en}

\section{la legislación de aguas}

Como se indicó más atrás, los aspectos estructurales de la legislación de aguas se refieren a la estabilidad de los derechos de agua y tierra asignados a la población, al reconocimiento de los derechos y usos consuetudinarios y a la transferibilidad de los derechos de agua.

\section{Estabilidad de los derechos de agua}

En la mayoría de las legislaciones las aguas, salvo excepciones, pertenecen al dominio público del Estado. Se observa una tendencia incipiente a considerar que el agua integra el patrimonio de la nación y que la declaración de que el agua es parte del patrimonio nacional suple y es equivalente a la declaración de que es de dominio público, en cuyos enunciados el agua es eliminada.

Esta concepción, que parece equiparar dominio público con patrimonio del Estado, es equivocada. $\mathrm{Pa}$ trimonio es un término contable, que a lo sumo puede ser considerado un término genérico, cuyo significado convencional es distinto al de dominio público. Si se cree que ambos términos son sinónimos, es mejor usar la expresión convencional "de dominio público". De lo contrario, el legislador, sin quererlo o sin así entenderlo, puede estar desafectando a las aguas de ese dominio público. Esta terminología ha sido utilizada en una propuesta de ley de aguas para Perú. En Francia, donde se ha usado el término "patrimonio de la nación" para referirse a las aguas, está claro que esto no convierte a las aguas privadas en aguas de dominio público. A juicio del autor de este artículo, es recomendable seguir usando la terminología convencional, salvo que el redactor de la ley, el Congreso, el Ejecutivo y la población toda del país de que se trate, tengan perfectamente claro que no quieren que las aguas y sus manifestaciones -como el río Marañón, el Amazonas, el Bío-Bío, el lago Titicaca- sean de dominio público. ${ }^{2}$

\footnotetext{
${ }^{2}$ Esta es la terminología, entre otras, de la legislación argentina (art. $2340 \mathrm{CC}$ ); de la chilena, que hab]a de bienes nacionales [cuyo dominio pertenece a la nación toda] de uso público (art. 589 del
}

Sin embargo los derechos otorgados a particulares para el uso de estas aguas tienen, en una gran mayoría de los sistemas, toda la protección de los derechos constitucionales de propiedad, siempre que se cumplan los objetivos y condiciones bajo los cuales aquéllos se otorgaron y reconocieron.

Los sistemas de derechos de aguas estables y ciertos tienden a incrementar la productividad, ya que los usuarios saben que sus inversiones en el desarrollo y conservación del recurso les significará una capitalización en su beneficio. Es por ello que cuando se producen cambios legislativos los usos preexistentes generalmente son reconocidos. Este es un principio tradicional en el derecho de aguas, cuyos orígenes se remontan al derecho romano, ${ }^{3}$ y que apunta a evitar la perturbación de las economías y de los usos existentes (Estados Unidos, Suprema Corte, 1984; Argentina, Corte Suprema de Justicia, 1987).

El respeto a los usos y derechos preexistentes a los cambios legislativos es un requerimiento de la estabilidad social. Su desconocimiento genera inestabilidad, y posiblemente tension, en la sociedad (Conac, 1989; Perrit, 1989).

La estabilidad de los derechos es un elemento que propicia la inversión económica y la conservación del recurso. Sin estabilidad legal no hay incentivos para invertir y conservar con miras al largo plazo (Cyriacy-

\footnotetext{
Código Civil y 5to, del Código de Aguas); de la ecuatoriana (art. 2, Ley de Aguas $\mathrm{N}^{\circ} 369$ ), y de la española (art. 2, Ley de Aguas $29 \%$ 1985). Es también la terminología de los Estados americanos (Naciones Unidas, 1972, p. 16). Esta terminología tiene características precisas, de entendimiento universal conforme a la ciencia del de. recho. Como el dominio público se define en forma expresa, al eliminar la vinculación entre agua y dominio público se podría argumentar que el recurso ha sido desafectado. Al menos otros dos autores parecen coincidir con la apreciación que aquí se hace: Gazzaniga (1993, p. 6) al comentar la ley de aguas de Francia de 1992 y García Montúfar (1995), refíriéndose al proyecto de ley de aguas para el Perú.

${ }^{3}$ Según la Lex Coloniae Genetivae luliae (43 A.D., del período de la República), las aguas vinculadas a las tierras públicas abiertas a los colonos están sujetas a los mismos usos y cargas que existían con sus propietarios anteriores. Sobre el período de la República, véase lo que explica Costa en Le Acque nel Diritto Romano, citado en Caponera, 1992, pp. 30 y 50.
} 
Wantrup, 1951; Cohen, 1967; Commons, 1950; Lee Gray y Nobe, 1975).

\section{Derechos y usos consuetudlnarios}

El tema de los derechos y usos preexistentes tiene gran importancia en el caso de las poblaciones indígenas, sobre todo cuando ellos se basan en normas consuetudinarias o en acuerdos o leyes del país en que las poblaciones autóctonas se radican.

En Estados Unidos y en Canadá los derechos de estas poblaciones han sido especialmente considerados y protegidos. Así, por ejemplo, los jueces canadienses han resuelto que los tratados y leyes deben interpretarse en forma equitativa, amplia y liberal en favor de los indígenas. La Suprema Corte de Justicia estadounidense ha sustentado una interpretación similar, diciendo que sería extremar las cosas creer que el Congreso quitó a los indígenas los medios para continuar con sus viejos hábitos de vida y que sin embargo no les dejó la posibilidad de cambiar a hábitos nuevos (Estados Unidos, Suprema Corte, 1908; Barlett, 1987).
América del Sur no ha efectuado aún un análisis detallado del tema de los derechos y usos de agua de sus poblaciones aborígenes. Sin embargo, recientes propuestas de legislación, sucesos y resoluciones judiciales en la región parecieran indicar que en ella las poblaciones aborígenes no han tenido la misma prioridad en las operaciones que sus contrapartes en Estados Unidos y Canadá (Véase el proyecto de ley de aguas del Perú; Latin American Weekly Report, 1994; Enríquez Vásquez y Real López,1992).

\section{Transferencia de derechos de agua}

Como consecuencia de la escasez relativa de aguas, a medida que aumenta la demanda del recurso se han producido cambios importantes en las modalidades de transferencia de derechos. Su aceptación como principio es importante para flexibilizar, dinamizar y optimizar el uso del agua. Al mismo tiempo, se hace necesario un análisis más detallado, faltante en la región, de los principales factores y condiciones de estos mercados en sistemas que tienen experiencia en la materia.

\section{III}

\section{Elementos regulatorios en la}

\section{legislación de aguas}

Los elementos regulatorios más importantes de la legislación de aguas tienden a proteger la base de recursos naturales, tanto en calidad como en cantidad, y a evitar la transferencia de externalidades negativas entre los usuarios del recurso. Los elementos regulatorios incluyen, entre otros, los siguientes:

i) Control público del recurso, a través del poder de policía del Estado o su titularidad por el sector público. Este control se expresa en la exigencia de permisos de uso y de vertimiento o descarga.

ii) Asignación de derechos de agua bajo la condición de que se haga uso efectivo y beneficioso de ella, incluyendo en algunos casos, reglas sobre su reutilización. El incumplimiento de esta condición usualmente acarrea la caducidad del derecho.

iii) Determinación por la ley de qué constituye uso beneficioso, incluyendo en algunos casos exigencias de respetar flujos y caudales mínimos, de conformidad con requerimientos ecológicos. iv) Establecimiento de sistemas de preferencias y prioridades entre los distintos usos posibles del recurso.

v) Control público de la calidad de las aguas, incluyendo normas de responsabilidad civil absoluta y solidaria por daños ambientales, estándares de descargas y de calidad de cuerpos receptores, control del uso de productos que afecten la calidad del agua, requerimientos tecnológicos y regulación del uso de suelos y áreas espaciales.

vi) Control público de los usos del agua, para asegurar que ella sea utilizada en conformidad con los derechos de agua otorgados. Este control incluye la realización de actividades de seguimiento: derechos de entrada e inspección, toma de muestras, derecho a requerir informaciones y registros, facultad para aprobar la construcción de obras de cierta envergadura, exigencias de prácticas de uso adecuadas, suspensiones de derechos en caso de prácticas inadecuadas o no auto- 
rizadas, y revocación de derechos en casos de infracciones y de no utilización.

vii) Protección de fuentes, puntos de abastecimiento y cursos de agua, protección y manejo de cuencas, prevención de la deforestación, preservación de áreas de recarga, planificación integrada del uso del recurso y uso conjunto de aguas superficiales y subterráneas. viii) Derecho de reasignación del recurso en casos de emergencia.

ix) Determinación y percepción de cargos y derechos financieros por el uso del agua.

x) Procedimientos expeditivos para la resolución de conflictos, y normas especiales para lidiar con situaciones de emergencia.

\section{IV}

\section{Condiciones para el uso del agua}

A continuación se detallan algunos aspectos fundamentales de la legislación moderna de aguas, según señala una muestra selectiva de leyes dictadas durante la última década.

\section{Generalidades}

La ley de aguas alemana, según enmiendas del 23 de septiembre de 1986, establece una serie de condiciones al uso del agua y a los permisos y licencias que se otorgan a este efecto. Así, la ley requiere el uso efectivo de los derechos de agua, la prevención de efectos perjudiciales, el pago de compensaciones, la evaluación preventiva de los efectos de determinados usos, la designación de cuidadores, la adopción de medidas correctivas de impactos nocivos y el pago de los costos del control común (art. 4). La legislación alemana permite la imposición de condiciones ex post al otorgamiento de un permiso o condición. Estas condiciones $e x$ post pueden resultar de necesidades económicas o ecológicas para el manejo apropiado de las aguas (art. 5). El sistema de control de los usos es extremadamente estricto: los derechos de aguas pueden ser revocados si no se utilizan, si no son necesarios, si hay cambio de uso no autorizado, si se usan más allá de la asignación estipulada en el permiso. Se requiere permiso tanto para usar aguas como para efectuar vertimientos en ellas; las solicitudes pueden ser rechazadas; los permisos y licencias se otorgan siempre para propósitos específicos. El permiso no significa que el Estado asuma un compromiso con el beneficiario de que éste siempre dispondrá de agua de una calidad o cantidad determinada. El uso por propietarios y ribereños no puede afectar adversamente a terceros, al agua, a los flujos y caudales ni al balance hídrico (arts. 15 y 24).
En Europa y en Asia actualmente se requieren permisos para el uso del agua, y la validez de los derechos está sujeta a que ese uso sea efectivo, al pago de cánones y tarifas, y a que no se causen daños al ambiente. Con frecuencia dichos permisos están sujetos a cambios y nuevas condiciones, según lo exijan las circunstancias y las necesidades ecológicas. En este ultimo sentido es interesante destacar que la reciente ley de aguas de Francia (1992) permite efectuar cambios en los derechos de aguas sin ofrecer compensación, cuando lo requiera la salud pública, o la seguridad general, cuando el medio acuático sea objeto de amenazas mayores, y en casos de abandono o mal mantenimiento de obras e instalaciones (art. 10, inciso iv). Otras leyes que merecen consideración a este respecto son la ley china de 1988, la ley de recursos hídricos inglesa de 1991 y la ley española de 1985. Esta última sujeta los derechos a condiciones de uso efectivo y beneficioso, so pena de caducidad (art. 64); también admite la modificación de las concesiones por "causa sobreviniente" (art. 63). La nueva ley de aguas de México también incluye una cláusula de uso efectivo de las aguas, so pena de caducidad (Téllez, 1993, pp. 110 y 111 ).

\section{Uso efectivo y beneficioso}

Entre las provisiones legislativas más importantes de la legislación de aguas merece un lugar destacado el requerimiento de uso efectivo y beneficioso de las aguas. Siendo el agua un recurso escaso, no hay razón alguna para permitir que un particular adquiera derechos de agua y no los use, pues con esto se daría margen a la especulación y a un posible enriquecimiento por el mero paso del tiempo, a costa de un bien de dominio público escaso, y objeto de demanda ecológica, 
social y económica. Si no se exige el uso beneficioso y efectivo del recurso se favorece los monopolios y el manejo del recurso como instrumento de competencia económica desleal: al bloquear el acceso al recurso se bloquea el ingreso de nuevos competidores y la expansión de la oferta de bienes y servicios.

Esto último es particularmente cierto en la minería de zonas áridas y en la generación de energía. Es por ello que la legislación norteamericana de zonas áridas, que se originó precisamente en la minería (prior appropiation), ha hecho un elemento fundamental del uso efectivo y beneficioso del recurso. Sin uso no hay derecho. El uso debe ser identificado y no debe contrariar el interés público involucrado en la utilización de las aguas. A tal punto esto se considera esencial, que en supuestos de cambio de legislación (tema que se considerará más adelante), los únicos usos que se reconocen y protegen son los que se han realizado efectivamente. Los usos deben ser eficientes y razonables. Evitar monopolios y especulación es una preocupación fundamental. La administración tiene la facultad permanente de exigir mayor eficiencia en la utilización del recurso para asegurar "el uso más extenso posible de los recursos naturales". El sistema se aplica en Colorado, Kansas, Dakota del Norte, Dakota del Sur, Arizona, Montana y otros estados. Es de interés público la utilización optima de las aguas del estado (Dakota del Sur). Los usos del agua no deben desembocar en especulación o desperdicio; deben ser socialmente aceptados y razonables. El método debe ser eficiente. No se quiere entregar a nadie un monopolio absoluto sobre el recurso, dándole más derechos de los que necesita para su uso efectivo y beneficioso; en pocas palabras, el agua no es un elemento para especulación, sobre todo si se considera que su asignación resulta de un acto público.

Por limitaciones de espacio no ahondaremos aquí en el tema; pero se recomienda una elaboración analítica al respecto antes de aprobar legislaciones de aguas que no exijan el uso efectivo y socialmente beneficioso del recurso. Se sugiere examinar en detalle la legislación estadounidense, por ser la que más claramente ha elaborado este principio, particularmente en la relación con la minería, la energía, y las necesidades de riego de la zona árida del país (Beck y Goplerud, 1991, p. 105 y siguientes).

El requisito de uso efectivo y beneficioso del recurso es a tal punto importante que también en la legislación de Estados Unidos ha sido un criterio aceptado para reconocer y proteger legalmente los usos preexistentes a cambios legislativos. En muchos esta- dos de ese país se aplicaba la calidad de ribereño como criterio para asignar derechos al uso del agua. Este sistema, que no propende al mejor uso, en sentido económico, fue paulatinamente reemplazado por el de permisos. Cuando esto sucedi 6 , muchos propietarios ribereños reclamaron que sus derechos de propiedad se veían afectados, puesto que lo que antes les correspondía como parte de su derecho de propiedad sobre la tierra, con los cambios legales sólo podían obtenerlo por permiso administrativo. Las cortes y jueces estadounidenses declararon en repetidas ocasiones que el cambio en los derechos de agua era un legítimo ejercicio del poder de policía del Estado, y de la regulación del dominio público, y que el único limite, a efectos de no infringir la garantía constitucional de la propiedad, era la necesidad de respetar los derechos adquiridos, solamente en la medida en que hubiera uso efectivo del recurso. Algunos estados (por ejemplo, Kansas, Oregon y Washington) establecieron un plazo para usar efectivamente el agua, más allá del cual Ios derechos en expectativa caducaban sin derecho a reclamo de no haber habido uso efectivo (Beck y Goplerud, 1991, vol. 1, p. 366 y siguientes).

Estos antecedentes son sumamente útiles para los países de América Latina cuya legislación hoy permite la existencia de derechos de agua sin exigir su uso efectivo. Cuando la escasez de recursos haga necesario un mejor uso de ellos y se consideren cambios de legislación estos países podrán tener presente lo expuesto sobre la legislación estadounidense.

A los países que estén en vías de implementar una nueva legislación, se les sugiere que bajo ningún concepto otorguen derechos de aguas sin obligación de hacer uso efectivo y beneficioso de ellos en un plazo determinado. La legislación comparada ofrece ejemplos más que suficientes de los problemas que genera omitir esa obligación y de las manipulaciones especulativas a las que queda expuesto un recurso fundamental como es el agua.

La ley de aguas de Chile no establece el requisito de uso efectivo y beneficioso de las aguas. Al respecto, es interesante citar experiencias sobre la aplicación de esta ley en el marco de la privatización masiva de servicios públicos vinculados al agua, proceso en el cual grandes actores institucionales llegan a ser protagonistas fundamentales del uso del agua, y ésta se convierte en un elemento básico de las estrategias con que las empresas de servicios buscan dominar el mercado:

Según señalan Bitrán y Sáez (1994, p. 50 y ss.), el sistema regulatorio se basa en la competencia en la generación de energía; sin embargo, en la práctica esta 
competencia no existe en Chile. ENDESA tiene aproximadamente un $65 \%$ de la capacidad de generación, y CHILGENER el 14\%. Los derechos de agua pertenecen fundamentalmente a ENDESA, que tiene un incentivo para evaluar proyectos sobre la base de la rentabilidad de su capacidad intramarginal, y obtiene un equilibrio monopólico de largo plazo posponiendo inversiones. En el mercado no pueden entrar nuevos empresarios pues no tienen derechos de agua para encarar los proyectos más eficientes. Los derechos de agua no debieron ser privatizados junto con las empresas, sino devueltos al Estado para ser entregados nuevamente, sujetos a una conđición de uso efectivo en plazo cierto.

Así, la experiencia chilena parece confirmar las razones por las cuales otras legislaciones hacen del principio de uso efectivo y beneficioso un elemento fundamental de su estructura legal de derechos de agua.

La monopolización a través de la creación de barreras de entrada mediante el control de insumos de producción esenciales y de recursos naturales, es un elemento clásico de la literatura económica (Sullivan, 1977 , pp. 25, 31 y 77). La existencia de mercados de agua no remedia necesariamente la situación, ya que muchas veces los insumos cruciales para la producción no son puestos en el mercado competitivo (Armstrong, Cowan y Vickers, 1994, p. 117 y nota al pie de la página 22).
Por lo expuesto pareciera que la falta de exigencias de uso efectivo y beneficioso del recurso, por un lado, y de mecanismos que corrijan acaparamientos monopólicos, por otro, tiene un efecto negativo sobre los mercados de agua y, en consecuencia, sobre la asignación eficiente de ella. Por esta razón se afirma que, con algunas excepciones, la evidencia empírica indica que los mercados de agua de Chile no han trabajado utilizando su pleno potencial. Bauer, en un trabajo seminal sobre el tema, señala que la ausencia de criterios de interés público en la ley chilena ha sido considerado por algunos como un elemento favorecedor de los monopolios y la especulación, y que el Gobierno virtualmente garantiza la subvaluación de los derechos de agua al no haber impuesto obligaciones en aras del interés público (Baver, 1995, pp. 2, 57 y 171).

Más aún, a falta de algún mecanismo institucional de caducidad o de la obligación de poner los derechos en el mercado, los incentivos para que los grandes usuarios institucionales vendan esos derechos son menores que las ventajas estratégicas de controlar un insumo de producción esencial en el marco de políticas corporativas de control de mercados. Por esta causa, en la discusión pública de la futura política energética de California, en un marco de mercado, se hace hincapié en la necesidad de no permitir que se monopolicen las fuentes de generación. ${ }^{4}$

\section{$\mathrm{V}$}

\section{Controles de calidad y medidas}

\section{de protección ambiental}

\section{Generalidades}

Las mismas razones que hacen que se busquen alternativas para asegurar el uso efectivo y beneficioso del agua demandan que se tomen medidas de protección ambiental. Estas medidas se establecen mediante leyes de aplicación general y obligatoria, combinadas con sistemas de sanciones y de responsabilidad objetiva, solidaria y absoluta por daño ambiental. En algunos casos esta responsabilidad puede ser retroactiva e incluir no sólo a quien causó el daño, sino también a sus inversores, financistas, y en el caso de empresas controla- das, a la empresa controladora del holding en la que se integra la empresa que causó el daño.

En algunos casos la responsabilidad por la contaminación se extiende a los funcionarios públicos y a

\footnotetext{
4 Véase California: R.94-04-031, I.94-04-032 COM/DWF DRAFT (WP6.1) p. -xxxvi; también el parrafo 68 de los "Findings of Fact"de] mismo documento, donde se concluye que la concentración de unidades de generación preocupa seriamente al Gobierno. Véase "Draft Policy Decision COM/DWF", misma nomenclatura númerica COM/ $\mathrm{JJK} / \mathrm{JLN}$ p.32, conforme a la cual se requeriría que los titulares que concentren unidades de generación deberán transferirlas.
} 
los empleados de la persona jurídica que contaminó. También se usan sanciones consistentes en multas diarias acumulativas por cada día de infracción; se crean sistemas de inspección, tomas de muestra, y requerimientos de información; se establecen patrones de calidad de los efluentes, los tratamientos y los cuerpos receptores; se exigen permisos de vertimiento y se crean normas especiales para controlar los contaminantes tóxicos; se aplican cargos financieros por contaminación, y se unifican los sistemas de manejo de calidad y cantidad en una sola entidad, que en Europa se organiza sobre la base de la cuenca hídrica.

Los sistemas se rigen pot algunos principios claves, los que incluyen: i) el principio de prevencion (control de contaminación en el origen); ii) el principio precautorio (establecida la posibilidad de contaminación grave, aun sin pruebas causales terminantes se requieren medidas de control), y iii) el principio de que quien contamina paga.

\section{Algunos ejemplos de doctrinas juridlcas crea- das con fines de protección ambiental}

En Alemania, la ley de 1986 impone el deber general de evitar la contaminación de las aguas y los cambios en detrimento de sus propiedades, requiriendo su uso económico en pro de la conservación de los recursos naturales de agua (art. 1 a). Demanda asimismo que las descargas en las aguas no sobrepasen un determinado contenido contaminante y que se regulen conforme a estándares tecnológicos de tratamiento. Exige el uso de la mejor tecnología disponible para controlar los elementos contaminantes tóxicos (art. 7). Los programas de control están a cargo de los Lander (estados o provincias). La responsabilidad por los daños que resulten de la contaminación es absoluta, objetiva, solidaria e indistinta (art. 22). La ley estipula además el mantenimiento de condiciones adecuadas de flujos, mantenimiento de la navegación, la atención a las necesidades ecológicas, y la protección de las características morfológicas, de las riberas y de la capacidad de autopurificación de los ríos.

Existe además una ley complementaria, sobre cobros por vertimientos, del 6 de noviembre de 1990 . Estos cobros consideran los niveles de peligrosidad de los efluentes, su toxicidad para los peces, los patrones de calidad establecidos para el cuerpo receptor, y las unidades de contaminación aguas abajo. Los cargos por contaminación son pagados por cualquier persona que descarga residuos en las aguas del país.

En los Países Bajos también hay una política de control de la contaminación, que está orientada primordialmente a hacer del país un lugar seguro y habitable, desarrollando y manteniendo sistemas de agua saludable que garanticen el uso y desarrollo sustentable del recurso.

Se han establecido tres principios fundamentales para controlar la contaminación de las aguas: reducción de la contaminación en la fuente; diseños hidráulicos apropiados y uso guiado y racional de los recursos de agua. El sistema de control incluye el manejo de la contaminación puntual y también de la difusa, en este último caso a través del control de ciertos productos y del uso del espacio. Los costos del control de la contaminación se sufragan a través del presupuesto ordinario (contribuyentes) y de contribuciones específicas de los contaminadores.

\section{La tutela pública}

Antes de cerrar el breve examen de estos temas, haremos referencia a la doctrina de la tutela pública (public trust), desartollada por los tribunales estadounidenses. ${ }^{5}$

En 1869 la legislatura de Illinois otorgó al ferrocarril derechos sobre el lecho del lago Michigan. Cuatro años más tarde dicha legislatura revoco la ley en que se basaba el otorgamiento de derechos sobre el lecho de ese lago. El ferrocarril argumento que esta revocación de la ley afectaba sus derechos de propiedad, resultantes de la ley anterior. La Corte Suprema de Estados Unidos declaró que la primera ley era inválida puesto que violaba el principio de la tutela pública en virtud del cual el estado de Illinois tenía derechos de propiedad sobre el lecho del lago. Esta tutela no es renunciable por el Estado a través de la transferencia de propiedad.

Este caso es muy interesante, puesto que el mismo principio se podría aplicar cuando la manera funcional de otorgar derechos sobre aguas equivalga a una alienación y transferencia del dominio público sobre el recurso. Un caso de posible aplicación del principio es el otorgamiento de derechos de agua sin plazo, sin obligación de uso y sin exigencia de uso efectivo. Este supuesto viola la tutela pública, puesto que el Estado se desprende funcionalmente de su deber y facultad de controlar el buen uso del bien de dominio público, al otorgar derechos incondicionados en cuanto a su uso y eternos en su duración. Si uno de los dos

\footnotetext{
${ }^{5}$ Caso Illinois Central Railtoad Co. vs. Illinois, 146 U.S. 387, 1982.
} 
elementos no está presente (obligación de uso efectivo y beneficioso o plazo limitado del derecho), la legislación sería inválida, puesto que violaría el principio de la tutela pública.

Este principio se ha aplicado también con motivos ambientales. En la legislación estadounidense el concepto de medio ambiente, según lo entiende la ley nacional de protección ambiental, es amplio y puede incluir no sólo el entorno natural sino también elementos sociales (Roger y Farber, 1992, pp. 28 y 29).
La tesis de la tutela pública también se ha aplicado para limitar derivaciones de caudales fundados en derechos de agua cuando tales derivaciones resultaban en la desecación de un lago natural. Esto se ha considerado notable en vista de lo sagrados que son los derechos de agua en los estados del oeste (Sullivan, 1977 , p. 295 y siguientes). De nuevo, esta aplicación de la doctrina podría ser útil en relación con el manejo de derechos de aguas otorgados, cuando el ejercicio de estos derechos tenga un impacto ambiental adverso.

\section{VI}

\section{Mercados de derechos de agua}

\section{Generalidades}

La comercialización de derechos de agua está considerada una buena alternativa para optimizar el uso de recursos escasos. También provee mecanismos para posponer obras costosas mediante la reasignación de las disponibilidades de agua existentes, por un precio, a usos de rentabilidad superior.

Los mercados de derechos de aguas son una característica distintiva del sistema legal del oeste estadounidense. En California, Nevada y Utah los derechos de agua se pueden transferir con independencia de los derechos sobre tierras. En otros estados, como Arizona, el agua sólo se puede transferir como accesorio a los derechos sobre tierras. La reasignación de derechos de agua es, con la sola excepción de los problemas de calidad del agua, la materia política más importante en el oeste árido de los Estados Unidos (Beck y Goplerud, 1991, vol. 2, p. 234).

El sistema estadounidense de transferencia de derechos de agua difiere fundamentalmente del sistema adoptado por la legislación chilena o por el código propuesto actualmente para el Perú, inspirado en el sistema chileno. En el sistema estadounidense, como se dijo más atrás, no se concibe un derecho de aguas válido desvinculado del uso efectivo y beneficioso de las aguas involucradas; las aguas no usadas no pueden transferirse, porque sobre ellas no existe derecho. En la legislación de los Estados Unidos el uso efectivo y beneficioso es la fuente, la causa, la medida, la razón de ser y la condición fundamental de los derechos de agua. No se pueden transferir derechos no efectivos ni utilizados, porque ellos simplemente no existen. Con este principio se busca evitar enriquecimientos especulativos de personas o firmas por el solo hecho de servir de intermediarios en la comercialización de un bien del dominio público de un estado o de la nación. Los aspectos relacionados con la prevención de monopolios ya han sido mencionados antes.

\section{Requisitos en los mercados de derechos de agua}

Según Anderson, el prestigioso tratadista norteamericano, para que una reasignación de aguas sea procedente debe cumplir con los siguientes requisitos fundamentales; i) las aguas deben haberse usado efectiva y beneficiosamente con anterioridad a la transferencia, y deben continuar usándose efectiva y beneficiosa mente con posterioridad a ella; ii) la reasignación no debe perjudicar a otros usuarios y debe favorecer el interés público, según sea autorizado administrativa o judicialmente de conformidad con el sistema que se aplique en el estado en cuestión.

Las transferencias fuera del área de origen (cuenca) no son siempre autorizadas. Por otra parte, no todos los estados admiten las transferencias de derechos de agua. ${ }^{6}$

\footnotetext{
${ }^{6}$ Vease una reseña más pormenorizada del tema, que incluye la compleja y detallada regulación estadounidense al respecto, en Anderson y Simmons, 1991, pp. 233 a 399.
} 


\section{Argumentos en favor de la regulación de los mercados de derechos de aguas}

El tema de los mercados de derechos de agua no está exento de polémica. Mientras que un buen número de expertos de alta reputación abogan por su implantación, otros igualmente prestigiosos expresan algunas reservas . Entre ellas destaca la preocupación por posibles efectos de concentración de derechos, pues son generalmente los usuarios con más recursos los que compran los derechos de los usuarios con menos poder económico. Aunque esto satisface los objetivos de optimización económica, preocupan los efectos sociales y ecológicos de tales procesos de concentración. Esto se ve claramente en el oeste de los Estados Unidos, en donde se están planteando conflictos en las transferencias de derechos de agua de granjeros y campesinos a las grandes ciudades. Los intereses en juego son el crecimiento de las ciudades, por un lado, y por otro la cultura, manera de vida, medio ambiente y futuro de las comunidades rurales, estructuradas alrededor de los usos agrícolas. Así, se ha afirmado que el sistema vigente de mercados de derechos de agua en ese país es incapaz de resolver equitativamente los conflictos vinculados a las transferencias de esos derechos (Ingram, 1989, p. 10).

Los mercados de derechos de agua son muy complejos, de modo que los procesos de transferencia se ven afectados por diversos factores, entre ellos: la prioridad del derecho transado; las características y el perfil del comprador y del vendedor; la flexibilidad geográfica en el uso del derecho transferido; la importancia económica de la operación; la confiabilidad del derecho; los volúmenes de agua transferidos; el sistema global de administración de aguas, y la economía de la región donde se realiza la operación (Colby, Crandall y Bush, 1993, pp. 1565 a 1572).

Debido a las complejidades señaladas, un número importante de expertos reclama que los mercados de derechos de agua, donde existan, sean adecuadamente regulados. Así, Babbit afirma: "La ausencia de control y regulación en materia de mercados de agua resulta en darwinismo económico-los grandes y poderosos prevalecerán".

Estas posiciones de cautela son razonables y pueden entenderse, puesto que en pocos casos las leyes económicas son absolutas (en las palabras de un juez en California, a juicio del tribunal la noción de

\footnotetext{
${ }^{7}$ Véase cita de Babbit en Ingram, 1989.
}

"maximizador racional de utilidad" es una elaboración económica que no tiene contrapartida en el mundo real, y por lo tanto no es base adecuada para fundamentar la decisión del caso presentado ante la corte), ${ }^{8}$ Pero lo cierto es que también se pueden citar ejemplos en los que la rigidez del sistema de asignación de aguas (en conjunción con otros factores institucionales, macroeconómicos y sociales) ha llevado a asignaciones ineficientes de recursos, a producción que supera la demanda efectiva, a inversiones innecesarias en infraestructura y, en algunos casos, a quiebras generalizadas en ciertas economías regionales sudamericanas.

\section{Regulación de los mercados de agua en el derecho estadounidense}

Los sistemas maduros de transferencia de derechos de agua aceptan tal transferencia en condiciones específicas y sujeta a control administrativo y público.

Entre los controles estadounidenses a las transferencias cabe mencionar los estatutos de algunos estados que prohiben transferir derechos de aguas (appurtenancy statutes) a fin de evitar especulaciones con las tierras; la aprobación de transferencias por organismos administrativos o judiciales que se otorga sólo en ciertas condiciones; la publicidad de las solicitudes de transferencia antes de que ellas sean aprobadas y la posibilidad de oposición pública o privada; la exigencia de que no se cause daños a terceros; la inscripción de la transferencia; el deber de mitigar los impactos ambientales adversos; la sujeción a evaluaciones del impacto ambiental; la imposición de condiciones que no tenía el derecho original y la necesidad de probar que se ha hecho uso efectivo y beneficioso del recurso antes de que se convalide la transferencia a través de un derecho formal de aguas en favor del adquirente. Si no se logra la aprobación, se produce la caducidad del derecho, incluso con una falta penal. Si se trata de distritos de riego, la aprobación debe incluir la del distrito cuando el derecho se transfiere fuera de él, y si se trata de derechos indígenas se necesita la aprobación del gobierno central (Blumm, 1991, pp.119 y siguientes).

Las transferencias deben servir el interés público y están sujetas a revisión en función de su efecto en la economía, la pesca y la caza, y la salud pública; de la pérdida de usos alternativos; de daños a otras perso-

\footnotetext{
${ }^{8}$ Caso "Natural Resources Defense Council vs. Duvall", $777 \mathrm{~F}$ Supp. 1533 (E.D. Cal. 1991).
} 
nas; del acceso público a aguas públicas, y de las calificaciones del adquirente, entre otros aspectos. Un elemento importante es la protección del interés público local y del área de origen del recurso. Y por último, cabe mencionar que para prevenir daños a terceros y a las fuentes de abastecimiento, las transferencias se limitan en principio a volúmenes históricamente consumidos y no a los de asignaciones nominales.

Los antecedentes mencionados reflejan la situación actual de los mercados de derechos de agua en Estados Unidos, área donde se cuenta con la mayor experiencia al respecto.

\section{La transferencia de derechos de agua en Amé- rica del sur}

El tema en América del Sur es aún incipiente. En algunos países el fuerte desarrollo de los sistemas de riego se ha llevado adelante con prohibición absoluta de transferir derechos; hoy parece requerirse un ajuste, puesto que las demandas se han diversificado e incrementado.

En otros lugares, como Chile, se permite la transferencia de derechos. El anteproyecto de ley de aguas para el Perú también autoriza transferencias. Sin embargo, en los dos modelos se han dejado de lado las prolijas y detalladas consideraciones de orden público, social y ambiental que se han descrito en el caso estadounidense. Esto, junto con la eliminación del requisito de uso efectivo y beneficioso del recurso, puede desembocar en monopolios, concentración del agua en pocas manos, restricciones a la competencia por la acumulación de derechos con propósitos oligopolísticos, y también en efectos sociales y ambientales adversos si son los sectores de menores ingresos los que transfieren sus derechos a aquéllos con más poder económico. Esto puede suceder porque se han tomado sólo los elementos de mercado del sistema de primera apropiación aplicado en el oeste de los Estados Uni- dos y se han marginado los elementos de interés público que son tan importantes en tal sistema.

Sobre la experiencia chilena se ha dicho que las transferencias han sido pocas, por limitaciones del sistema institucional, de los títulos de los derechos de agua y de la base física de regulación del recurso, y también por los costos de transacción, la falta de conocimiento legal y las resistencias culturales. El Código de Aguas chileno también ha sido criticado por tener una "falla crítica en su lógica económica: los derechos de aguas son gratis" (Bauer, 1993, pp. 1 a 4). Pero los partidarios del sistema afirman que esto es irrelevante, pues tiene que ver sólo con la distribución inicial de la renta y no con la eficiencia económica de la asignación a través del sistema de mercado (lo único que importa es que los derechos sean libremente transferibles).

Se ha dicho también que el Código chileno falla en sus aspectos económicos, y que lo que ha contribuido a mejorar los rendimientos agrícolas han sido los subsidios al riego (ley 18450) y el sistema de comercialización. En lo que hace a la equidad del funcionamiento del sistema en Chile, Bauer argumenta que los efectos de éste pueden haber sido negativos, ya que los pequeños propietarios no tenían información o recursos para beneficiarse de él. El mismo autor critica la operatividad de los mercados, que ha sido limitada, aduciendo que el sistema institucional cré condiciones para que las transacciones de aguas no fueran incentivadas. El sistema puede haber contribuido a que los usuarios pequeños perdieran sus derechos (Bauer, 1993 , p. 3). El tema de la equidad preocupa actualmente a organismos como el Banco Mundial y sus consultores (Simpson, 1994, pp. 30 a 33) que se preguntan cómo operaría el sistema en una agricultura de subsistencia, y estiman que la inadecuada distribución del acceso a porciones importantes de los recursos productivos contribuye a la degradación ambiental (Banco Mundial, 1990, pp. 42 a 44).

\section{VII}

\section{Conclusiones y recomendaciones de}

\section{política legal}

En la mayoría de los países del mundo existe una preocupación seria por el manejo integrado de los recursos hídricos, su conservación y la prevención de mo- nopolios basados en ellos. Sin embargo, en América del Sur se tiende a creer que el otorgamiento de derechos incondicionados sobre las aguas asegura que los 
mercados solucionarán automáticamente los problemas que se puedan presentar. La práctica parece demostrar que no es así. En Chile hay problemas de monopolios, de resolución de conflictos cuando median partes múltiples, y de subordinación del aspecto ambiental, que es secundario al aprovechamiento económico.

Es por ello que en Chile hay propuestas de reforma a la legislación de aguas. Estas incluyen tanto la posibilidad de establecer condiciones de caducidad como la de imponer patentes o impuestos al uso del agua, para evitar el bloqueo de los mercados a través de acaparamientos por razones especulativas. Sin embargo, como los derechos otorgados en Chile to han sido sin condiciones de ningún tipo, y sobre todo sin requisitos de uso efectivo y beneficioso, algunos afirman que las medidas tendientes a modificar las condiciones de esos derechos requerirían reforma constitucional.

Este autor no coincide con tal apreciación, pues su efecto práctico, sería que en Chile las aguas tendrían el carácter de funcionalmente privadas. Hemos visto antes que situaciones similares en Estados Unidos fueron resueltas con la imposición de condiciones a los derechos de agua como ejercicio legítimo del poder de policía sobre un bien de dominio público. Más aún, en el caso del Lago Michigan el otorgamiento de derechos de propiedad sobre un bien sujeto a tutela pública se estimó nulo, pues el Estado no puede renunciar a esa tutela. La analogía con el caso chileno es clara: si los bienes son de dominio público, sigue rigiendo el deber de tutela. Si no lo son por la forma en que se otorgan los derechos, habría habido una cuestionable alienación funcional del dominio público, puesto que la propiedad pública sería sólo un rótulo sin contenido.

No obstante, el fin de este artículo no es encontrar cómo revertir el caso chileno - el que, consideraciones legales y de derecho comparado aparte, está vinculado a su tiempo y espacio y a la filosofía politica imperante- sino demostrar que pese a existir situaciones de monopolio y especulación, como señalan varios autores, una vez que se entregan derechos incondicionados es muy difícil revertir las situaciones creadas. Por ello es fundamental que las reformas a la legislación de aguas en América del Sur no entreguen derechos de agua incondicionados. La obligación de uso efectivo y beneficioso del recurso, y el amparo por el trabajo, son mecanismos de prevención de monopolios.

Una vez establecida la obligación de ese uso, es lógico preguntarse qué pasa si no se cumple con ella en el plazo legal o convencional establecido. Al respecto cabrían tres opciones:

a) Vencido el plazo sin que se haya hecho uso del recurso, por razón justificada, los derechos caducan y revierten al mercado a través del Estado. El bloqueo del mercado se levanta así por la acción del Estado y de la norma legal. Esta es la solución que hemos visto en el derecho estadounidense, el mexicano, el español y el argentino, y que a juicio de este autor es conveniente y expeditiva. Tiene la ventaja de que el Estado se halla en la obligación de declarar la caducidad, y de que un particular puede denunciar la situación y requerir acción.

b) Vencido el plazo sin que se haya hecho uso del derecho, el Estado está obligado a llamar a subasta pública, de oficio o a petición de parte. Los procedimientos son simples, y el bien se reintegra al mercado en forma inmediata. El bloqueo al mercado termina por las fuerzas del mercado. El requerimiento de remate una vez vencidos los plazos es de utilidad pública, y el Estado no puede negarse. Como el beneficiario caducado no hizo inversiones de uso, los recursos recaudados pasan a un fondo general de manejo de aguas o a rentas generales; el beneficiario caducado no puede participar en la subasta. Esta alternativa es simple, elimina la discrecionalidad del Estado y permite el pronto retorno de los bienes al mercado, por la dinámica de éste. Por otra parte, acaba con la propiedad de "manos muertas" y disuade y controla los monopolios. En suma, el mercado actúa como corrector funcional.

c) Por último, se ha sugerido que el problema de los derechos especulativos, monopólicos y no usados se solucione con un impuesto, patente o, en general, un cobro sobre las aguas no usadas. A juicio de este autor, de todos los sistemas este es el menos conveniente, ya que:

i) habría que determinar los costos de oportunidad de cada beneficiario no usuario, lo que no es tarea menor porque requiere un alto grado de información y seguimiento, y un aparato regulatorio sofisticado; ii) para determinar los costos de oportunidad habría que obtener información de las empresas que serían afectadas por el impuesto u otro cobro, la que sería difícil de conseguir o distorsionada (al respecto es útil recordar la información insuficiente o asimétrica respecto a servicios públicos privatizados); iii) habría que establecer un impuesto lo suficientemente alto como para ser disuasivo. Cabe suponer que las grandes empresas de servicios públicos que monopolizan agua tendrán capacidad más que suficiente para influir en los procesos y controlar su resultado. El fenómeno de 
cooptación del regulador es bien conocido en los servicios públicos, y no hay razón para que no se dé en el manejo del agua; iv) por último, todo el proceso de determinación de los costos de oportunidad y de los cobros, así como su implementación, estaría afectado por un alto grado de discrecionalidad del Estado, y sujeto a su expeditividad.

A juicio de este autor los mercados de derechos de agua son, en condiciones de regulación y control adecuadas, un instrumento idóneo para promover asignaciones más eficientes de los recursos hídricos. Estas condiciones incluyen, entre otros aspectos, los sigujentes: i) información adecuada; ii) legislación idónea y derechos claros y confiables; iii) un sistema adecuado de administración, catastro y registro de recursos hídricos y derechos de agua; iv) un sistema eficiente de almacenamiento y conducción de agua; v) exigencia de uso efectivo y beneficioso del recurso; vi) escrutinio y control público de las transferencias, con posibilidad de oposición conforme se ha detallado en este informe y con normas especiales para los sectores con menos educación, información o ventajas culturales.

Las condiciones detalladas precedentemente son requisitos previos. Sin ellas la implementación de un sistema de mercados de aguas redundará en serios problemas y en conflictos sociales y económicos.

\section{Bibliografía}

Anderson, O.L. y P. Simmons (1991): Reallocation, R. Beck y , Goplerud, Waters and Water Rights: Riparianism and Prior Appropriation, Charlottesville, Va., Estados Unidos, The Michie Company.

Argentina, Corte Suprema de Justicia (1987): La Pampa c., Mendoza, L-195-XVIIl.

Armstrong, M., S. Cowan y J. Vickers (1994); Regulatory Reform: Economic Analysis and British Experience, Cambridge, Mass., Estados Unidos, The MIT Press.

Banco Mundial (1990): The World Bank and the Environment: First Annual Report, Washington, D.C.

Banco Mundial/CEPAL (1994); Water Legislation: an Integrated Approach. Washington, D.C., Carnegie Conference Center, 8 y 9 de septiembre.

Barlett, R. (1987): Prior and paramount aboriginal water rights in Canada, revision de libro, Resources, The Newsletter of the Canadian Institute of Resource Law, $\mathrm{N}^{\circ} 18$.

Bauer, C. (1993): Derechos de propiedad y el mercado en una institucionalidad neoliberal: efectos e implicancias del Código Chileno de Aguas de 1981, tesis doctoral, Santiago de Chile, agosto.

(1995): Against the Current? Privatization, Markets and the State in Water Rights: Chile, 1979-1993, Berkeley, Calif., Estados Unidos, Universidad de California.

Beck, R. y C.P. Goplerud (1991): Waters and Water Rights: Riparianism and Prior Appropriation, Charlottesville, Va., Estados Unidos, The Michie Company.

Bitrán E. y R.E. Sáez (1994): Privatization and regulation in Chile, B.P. Bosworth, R. Dornbusch y R. Laban (eds.), The Chilean Economy: Policy Lessons and Challenges, Washington, D.C., The Brookings Institution.

Blumm, M.C. (1991): Reserved Water Rights, R. Beck y C.P. Goplend, Waters and Water Rights: Riparianism and Prior Appropriation, vol. 4, Charlotesville, Va., Estados Unidos, The Michie Company.

Caponera, D. (1992): Principles of Water Law and Adninistration, Países Bajos, Balkema.

Cohen, M. (1967): Law and the Social Order, Nueva York, Anchor Books.

Colby, B., K. Crandall y D. Bush (1993): Water rights transactions, market values and price dispersion, Water Management Research, vol. $29, \mathrm{~N}^{\circ} 6$, junio.
Commons, J.R. (1950): The Economics of Collective Action, Nueva York, The Mac Millan Company.

Conac, F. (1989): Land and water rights issues in irrigated schemes in Sub-Saharan Africa and Madagascar-Conflicts that might be avoided, DVWK Bulletin, $\mathrm{N}^{\circ} 16$, Hamburgo, Verlag Paul Parcy.

Cyriacy-Wantrup, S.V. (1951): Collars and Sense in Conservation, Circular $\mathrm{N}^{\circ} 402$, Berkekey, Calif.. Estados Unidos, Universidad de California.

Enriquez Vázquez, M. y B. Real López (1992): Vida por petróleo: El caso del pargue nacional Yasuni ante los tribunales, Qujto. Fundación Ecuatoriana de Estudios Sociales

Estados Unidos, Suprema Corte (1908): Winters vs. United States. 207 US 564, Washington, D.C

(1984): Syllabus and Opinions, $\mathrm{N}^{\circ} 80$, Washington, D.C.

García Montúfar (1995): Comentario en El Universal, Lima, 21 de junio, p. B6.

Gazzaniga, J. L. (1993): Loi sur l'eau du 3 janvier 1992, Environment, fascículo 610, 8, Francia, Editions Techniques-JurisClasseurs.

Ingram, $H$. (1989): The trust doctrine and community values in water, World Conference on Water Law and Administration. Valencia, España.

Latin Aunerican Weekly Report (1994): Two dead as protests against end of land reform spread through Ecuador, Londres, Latin American Newsietter, 30 de junio.

Lee Gray, S. y K. Nobe (1975): Water resources economics, externalities and institutions in the United States, Global Water Law Systems, presentado a la World Conference on Water Law and Administration, Valencia, España. Asociación Internacional de Derechos de Aguas.

Naciones Unidas (1972): Abstraction and Use of Water, Nueva York.

Naciones Unidas, Consejo Económico y Social (1993): Permanent sovereignty over minerals and water resources, Report of the Secretary General, Nueva York, Comité de Recursos Naturales.

(1994): Legislative and institutional aspects of water resources management: Institutional and legal issues in water resources management, Report of the Secretary General, Nueva York, Comité de Recursos Naturales.

Perú, Ministerio de Agricultura (1994): Proyecto de Ley Orgánica de Aguas para el Perú, junio. 
Perrit, R. (1989); Proceedings of the African Experiente with River Basin Development, Washington, D.C., USAID African Bureau.

Roger, R. F. y Daniel A. Farber (1992): Environmental Law, Nutshell Series, St. Paul. Minn., Estados Unidos, West Publishing Company.

Simpson, L. (1994): Os mercados de agua são uma opção viabel?, Finanças e desenvolvimento, vol. $14, \mathrm{~N}^{\circ} 2$, Washington, D.C.
Fondo Monetario Intemacional (FMI)/Banco Interamericano de Desarnollo (BID), junio.

Sullivan, L.A. (1977): Antritrust, St. Paul, Minn., Estados Unidos, West Publishing Co.

Téllez, L. (1993): Nueva legislación de tierras, bosques y aguas, México, D.F., Fondo de Cultura Económica (FCE). 